\title{
EDUCAÇÃO EM TEMPO INTEGRAL: ALGUNS DESAFIOS PARA A GESTÃO ESCOLAR
}

\author{
EDUCACIÓN EN TIEMPO INTEGRAL: ALGUNOS DESAFÍOS PARA LA GESTIÓN \\ ESCOLAR
}

\section{INTEGRAL FULL-TIME EDUCATION: SOME CHALLENGES FOR SCHOOL MANAGEMENT}

Elisangela da Silva BERNADO ${ }^{1}$

RESUMO: O presente tema de pesquisa se justifica em função do cenário atual da gestão escolar, o qual exige qualificação para o exercício de diferentes funções nas unidades escolares de tempo integral. Com a finalidade de investigar os possíveis impactos do Programa Mais Educação nos resultados educacionais, o objetivo deste artigo foi analisar percepções e desafios de gestores escolares de estabelecimentos de ensino de tempo integral em seis escolas públicas cariocas. $\mathrm{O}$ exercício da gestão não é mais uma função meramente burocrática, mas é uma ação que exige articulação entre os saberes, os tempos e os espaços formais e não formais de ensino, da comunidade e da gestão. Este movimento gera a necessidade de uma gestão diferenciada, que atenda às atuais perspectivas que marcam uma outra lógica de gestão escolar, especialmente no que se refere ao planejamento, à coordenação e à avaliação de sistemas de ensino.

PALAVRAS-CHAVE: Gestão escolar. Educação em tempo integral. Programa mais educação.

RESUMEN: El presente tema de investigación se justifica en función del escenario actual de la gestión escolar, el cual exige cualificación para el ejercicio de diferentes funciones en las unidades escolares de tiempo completo. Con el fin de investigar los posibles impactos del Programa Más Educación en los resultados educativos, el objetivo de este artículo fue analizar percepciones y desafios de gestores escolares de establecimientos de enseñanza de tiempo completo en seis escuelas públicas cariocas. El ejercicio de la gestión no es más que una función meramente burocrática, pero es una acción que exige articulación entre los saberes, los tiempos y los espacios formales y no formales de enseñanza, de la comunidad y de la gestión. Este movimiento genera la necesidad de una gestión diferenciada, que atienda a las actuales perspectivas que marcan otra lógica de gestión escolar, especialmente en lo que se refiere al planeamiento, a la coordinación ya la evaluación de sistemas de enseñanza.

PALABRAS CLAVE: Gestión escolar. Educación a tiempo completo. Programa más educación.

${ }^{1}$ Universidade Federal do Estado do Rio de Janeiro (UNIRIO), Rio de Janeiro - RJ - Brasil. Coordenadora do Mestrado em Educação do Programa de Pós-Graduação em Educação/PPGEdu. ORCID: https://orcid.org/00000003-3994-0254. E-mail: efelisberto@yahoo.com.br 
ABSTRACT: The present research theme is justified according to the current school management scenario, which requires qualification for the exercise of different functions in full-time school units. With the purpose of investigating the possible impacts of the Program More Education on educational outcomes, the objective of this article was to analyze the perceptions and challenges of school managers of full - time educational establishments in six public schools in Rio de Janeiro.The exercise of management is no longer a purely bureaucratic function, but it is an action that requires articulation between formal and nonformal learning, times and spaces of teaching, community and management. This movement generates the need for a differentiated management that takes into account the current perspectives that mark another logic of school management, especially in planning, coordination and evaluation of education systems.

KEYWORDS: School management. Full-time education. Program more education.

\section{Introdução}

Foi no contexto de democratização do acesso à escola e de aumento da escolaridade obrigatória que vieram à tona as desigualdades educacionais e sociais e a necessidade de se fazer um acompanhamento dos sistemas de ensino e da implementação de programas em busca da melhoria da qualidade da educação por meio de levantamentos educacionais.

No contexto histórico brasileiro, nos anos 80, o impacto destas pesquisas e suas influências sobre a política e a pesquisas educacionais, servem como ponto de partida para a compreensão da educação que se insere num contexto de redemocratização política da sociedade brasileira, onde é notável tanto a universalização do ensino do antigo primeiro grau quanto o aumento do processo de seletividade escolar, o crescimento da população e o aceleramento da urbanização.

E a partir dos anos 90, começaram a ser implementadas políticas de descentralização administrativa, financeira e pedagógica da educação, como também políticas de correção de fluxo escolar (organização do ensino em ciclos) e de ampliação da jornada escolar via programas indutores da educação de tempo integral, como o (antigo) Programa Mais Educação - PME - (BRASIL, 2007; BRASIL, 2010) e o Programa Novo Mais Educação PNME - (BRASIL, 2016).

O presente tema de pesquisa se justifica em função do cenário atual da gestão escolar, o qual exige qualificação para o exercício de diferentes funções nas unidades escolares de tempo integral. O exercício da gestão não é mais uma função meramente burocrática, mas é uma ação que exige articulação entre os saberes, os tempos e os espaços formais e não formais de ensino, da comunidade e da gestão. Frente às variadas perspectivas políticas e pedagógicas das instituições públicas de ensino, a gestão se impõe como fundamental no 
campo das exigências sociais e pedagógicas. Este movimento gera a necessidade de uma gestão diferenciada, que atenda às atuais perspectivas que marcam uma outra lógica de gestão escolar, especialmente no que se refere ao planejamento, à coordenação, ao acompanhamento e avaliação de sistemas de ensino.

Neste sentido, com a finalidade de investigar os possíveis impactos do Programa Mais Educação nos resultados educacionais, o objetivo deste artigo foi analisar percepções e desafios de gestores escolares de estabelecimentos de ensino de tempo integral em seis escolas públicas cariocas.

$\mathrm{Na}$ pesquisa realizada trabalhamos com as duas abordagens, quantitativa (por meio de análise de bases de dados educacionais) e a qualitativa (por meio de observação e realização de entrevistas). No total foram 25 sujeitos entrevistados em seis escolas públicas localizadas na região da Grande Tijuca/RJ. Para o recorte deste artigo, optamos por apresentar parte dos resultados qualitativos das entrevistas realizadas com os diretores das escolas participantes.

Este artigo está organizado em três seções, além desta Introdução e das considerações finais. A próxima seção traz o referencial teórico desenvolvido na pesquisa, a segunda os procedimentos metodológicos da investigação e a terceira seção alguns achados e pistas da pesquisa para pensarmos em políticas educacionais em busca da efetiva melhoria da qualidade da educação.

\section{O estudo da escola como uma organização social: os desafios para a redução das desigualdades sociais}

Nestas duas seções apresentamos o referencial teórico da pesquisa. Na primeira dialogamos com investigações que trazem a escola enquanto objeto de estudo e análise; e na segunda seção trazemos um programa indutor de educação em tempo integral em busca de uma maior ampliação da jornada escolar e da igualdade de oportunidades na perspectiva de uma gestão democrática - o Programa Mais Educação (PME).

Bom, a escola, enquanto objeto de estudo e análise, tem sido estudada por inúmeros autores (CANÁRIO, 1996; NÓVOA, 1992, entre outros). Na concepção de Canário (1996), o que contribuiu para uma focalização da escola como instituição, e mais tarde como organização, foram as condições sociais ligadas à designada "crise da escola", por uma profunda insatisfação por seu funcionamento. $\mathrm{O}$ autor argumenta que a expansão dos sistemas escolares teve por base dois pressupostos associados a visões otimistas da escola: um deles tinha como referência a teoria do capital humano, que estabelecia uma relação entre 
investimento da educação escolar e desenvolvimento econômico e o outro tinha como referência o princípio da igualdade de oportunidades. Bourdieu; Passeron (1992) reiteram que esses dois pressupostos não se concretizaram e que o insucesso escolar revelou uma escola reprodutora das desigualdades sociais em vez de corrigi-las.

Uma das influências mais significativas do estudo da escola na tomada de decisão política diz respeito à forma como têm sido apropriados alguns resultados da investigação produzida sobre os efeitos da escola e das escolas eficazes. Uma interpretação de muitas dessas investigações tem servido para legitimar medidas de política educacionais (reformas globais da administração e gestão das escolas) que visam generalizar, por via administrativa, as características identificadas nas “escolas eficazes", procurando desenvolver a autonomia da escola na alocação e distribuição de recursos, reforçando o sentido de "gestão centrada na escola" (BARROSO, 1996).

Barroso (1996) afirma que a investigação que tem sido realizada sobre as escolas que adotam este modelo de gestão deu lugar ao aparecimento de uma corrente crítica dos princípios e critérios relacionados a tal modelo. Esta perspectiva crítica questiona dois pontos essenciais: a filiação nas políticas neoliberais que visam promover um "mercado da educação" por meio da privatização disfarçada da escola pública e a introdução, sob pretexto de aumentar a eficácia e a eficiência da escola, de uma tecnologia de controle e dominação, através das estruturas organizativas e modos de gestão que são postos em prática. No que se refere ao estudo da escola, esta abordagem crítica permitiu que as escolas fossem vistas como construções sociais, sendo valorizados o papel dos indivíduos e o contexto sócio-histórico (idem, 1996).

Nos anos 50 e 60, temos vários estudos americanos e europeus que sugeriram que as escolas tinham pouca influência na explicação da trajetória escolar discente. O Relatório Coleman, pesquisa realizada na década de 60, baseado num amplo levantamento de dados, que envolveu 645.000 alunos norte-americanos, constatou que o desempenho escolar dos alunos era quase completamente determinado pelo seu contexto socioeconômico e que as escolas pouco ou nada podiam fazer para modificar essa realidade. Isto é, a escola não fazia diferença no desempenho escolar dos alunos. As pesquisas sobre escola eficaz se interessam justamente por essas escolas e salas de aula que fazem a diferença. Entendendo-se como escola (ou sala de aula) eficaz àquela que melhora a aprendizagem dos seus alunos (qualidade), principalmente os alunos que têm sua origem socioeconômica menos favorável, e diminuem as diferenças de desempenho entre os diferentes alunos (equidade). 
Nóvoa (1992) toma a escola como objeto autônomo de estudo e como espaço privilegiado de inovação educacional. Apontando que os estudos clássicos revelaram de que forma as variáveis sociais, culturais e familiares interferem no sucesso dos alunos, mas foram os sociólogos dos anos seguintes (década de 70) que prolongaram suas reflexões, indicando que as diferenças entre os alunos só se transformam em desigualdades devido à estrutura e ao funcionamento do sistema educativo (influência das variáveis escolares e dos processos internos dos estabelecimentos de ensino no desempenho escolar do aluno). A emergência de uma sociologia das organizações escolares, situada entre uma abordagem micro (centrada na sala de aula) e macro (perspectivas sócio-institucionais centradas no sistema de ensino), faz emergir um olhar meso de compreensão e análise da escola (NÓVOA, 1992).

A reflexão sobre a escola tem sempre como pano de fundo determinadas concepções da sociedade e do indivíduo. Tomar consciência destas diferentes concepções permite-nos oferecer um quadro de análise sobre a organização escolar. A abordagem sociológica da escola apresenta duas grandes concepções. A primeira concepção centra a sua atenção sobre o sistema (sociedade), considerando que o indivíduo é determinado pelos condicionalismos do sistema. Esta perspectiva teve uma grande influência na análise da escola até o final da década de 80 , e a segunda concepção considera que existe a necessidade de levar em conta a construção social da realidade, onde o indivíduo tem um papel ativo. Esta perspectiva tem assumido grande relevo a partir da década de 80 (MOURA, s/d).

Estas duas grandes abordagens sociológicas acentuam duas dimensões distintas na organização escolar: a da desigualdade e a da inovação. Também ao longo desta seção do artigo, procuramos refletir sobre a escola a partir da primeira perspectiva, apresentando uma síntese da literatura mais relevante sobre esta dimensão. Desta forma, procuramos contribuir para uma reflexão mais sistematizada acerca da problemática da organização escolar, mostrando como um determinado paradigma de análise pode influenciar a nossa visão sobre a escola.

A perspectiva sociológica das desigualdades escolares insere-se no contexto socioeconômico no final dos anos 60 e centra-se na natureza coerciva da sociedade e na estratificação da sociedade. "Os teóricos do conflito vêem os sistemas sociais divididos em grupos dominantes e dominados. [...] O grupo dominante também impõe os seus próprios valores e a sua visão do mundo aos seus subordinados." (PARELIUS; PARELIUS, 1987 apud MOURA, s/d). Esta perspectiva sociológica olha para a educação escolar como um meio pelo qual esta estratificação se reproduz e se efetua a imposição dos valores e ideias das classes 
dominantes. Esta corrente sociológica assume uma posição totalmente diferente em relação à ordem social e ao papel da escola.

Diversos estudos na década de 60 foram muito importantes não só para desmistificar a ideia de que a escola é o grande instrumento da sociedade para assegurar a igualdade de oportunidades entre os seus membros, como também serviram de base às reflexões de muitos teóricos do conflito. O estudo que maior projeção teve em termos científicos (e também políticos), quer pela dimensão da população estudada, quer pela controvérsia que alimentou, foi o Relatório Coleman (1966), como já mencionado anteriormente. Uma das grandes conclusões deste estudo é a verificação de que as diferenças entre os grupos sociais tendem a manter-se ou a aumentar com a escolarização.

Assim, a abordagem de análise da escola deve ser sistêmica, ou seja, a organização escolar deve ser considerada e abordada como um todo. O estabelecimento de ensino é muito mais do que a soma das suas partes. As teorias 'explicativas' das desigualdades no seio da escola mostram-se importantes para uma análise da realidade escolar. Estas teorias tiveram uma contribuição para rompimento do "mito" de que a educação promove a igualdade. Ao contrário, muitas vezes a educação não só mantém, como pode até promover as desigualdades sociais. A organização da escola e das turmas não é neutra e tem efeitos nos resultados escolares dos alunos. Logo, tal perspectiva acaba acentuando a escola como reprodutora de desigualdades sociais, permitindo deste modo a consolidação de uma estratificação educacional no interior dos estabelecimentos escolares.

Na próxima seção trazemos um programa indutor de educação em tempo integral em busca de uma maior ampliação da jornada escolar e da igualdade de oportunidades na perspectiva de uma gestão democrática - o Programa Mais Educação (PME).

\section{O Programa Mais Educação: um programa indutor de educação em tempo integral}

O Programa Mais Educação, criado pela Portaria Interministerial no. 17/2007 e regulamentado pelo Decreto n. 7.083/10, aumenta a oferta educativa nas escolas públicas por meio de atividades optativas que foram agrupadas em macrocampos, como acompanhamento pedagógico, meio ambiente, esporte e lazer, direitos humanos, cultura e artes, cultura digital, prevenção e promoção da saúde, educomunicação, educação científica e educação econômica.

A Portaria Normativa Interministerial n. 17, de 24 de abril de 2007, demonstra as considerações, as finalidades, os objetivos e característica do PME. No Parágrafo único do Artigo $1^{\circ}$, afirma que: 
O programa será implementado por meio do apoio à realização, em escolas e outros espaços sócio-culturais, de ações sócio-educativas no contraturno escolar, incluindo os campos da educação, artes, cultura, esporte, lazer, mobilizando-os para a melhoria do desempenho educacional, ao cultivo de relações entre professores, alunos e suas comunidades, à garantia de proteção social da assistência social e à formação para a cidadania, incluindo perspectivas temáticas dos direitos humanos, consciência ambiental, novas tecnologias, comunicação social, saúde e consciência corporal, segurança alimentar e nutricional, convivência e democracia, compartilhamento comunitário e dinâmica de redes (BRASIL, 2007).

Como proposta de uma política indutora de educação em tempo integral, o Programa Mais Educação tem por finalidade contribuir para a melhoria da aprendizagem por meio da ampliação do tempo e permanência de crianças, adolescentes e jovens matriculados em escola pública, mediante oferta de educação básica em tempo integral (Decreto n. 7.083/2010, $\left.\operatorname{art} .1^{\circ}\right)$.

O programa visava fomentar atividades para melhorar o ambiente escolar, tendo como base estudos desenvolvidos pelo Fundo das Nações Unidas para a Infância (UNICEF), utilizando os resultados da Prova Brasil de 2005. Nesses estudos destacou-se o uso do "Índice de Efeito Escola (IEE)", indicador do impacto que a escola pode ter na vida e no aprendizado do estudante, cruzando-se informações socioeconômicas do município no qual a escola está localizada. Por esse motivo a área de atuação do programa foi demarcada inicialmente para atender, em caráter prioritário, as escolas que apresentam baixo Índice de Desenvolvimento da Educação Básica (IDEB), situadas em capitais e regiões metropolitanas.

$\mathrm{O}$ atual Plano Nacional de Educação (PNE), sancionado pela Lei 13.005, de 25 de junho de 2014, propõe em sua sexta meta oferecer educação em tempo integral em, no mínimo, 50\% das escolas públicas, de forma a atender, pelo menos, 25\% dos (as) alunos(as) da educação básica (BRASIL, 2014). Como já exposto, a meta 6 compreende uma proposta de ampliação da jornada diária de forma gradual nas escolas públicas brasileiras. Atualmente, a educação em tempo integral ganhou destaque no Brasil, surgindo, assim, diversas iniciativas impulsionadas pelo governo e organizações da sociedade civil, no intuito de melhorar o ensino público e superar as desigualdades sociais e educacionais existentes no país (SOUSA; ESPIRITO SANTO; BERNADO, 2015).

No Brasil, alguns grupos de diferentes tendências e correntes discutiram ao longo do tempo sobre a educação integral, e, dentre esses, os católicos, os quais defendiam uma educação integral voltada para atividades intelectuais, físicas, artísticas e ético-religiosas, aliadas a uma disciplina rigorosa. Já nos anos de 1930, Anísio Teixeira tem grande destaque, 
pois ele refletia acerca das instituições públicas e as implementava tendo como um de seus objetivos uma formação completa, que segundo a autora muito se aproximava de uma “educação integral". Anísio Teixeira defendia a construção de um currículo em que se desenvolvessem atividades cognitivas, físicas e estéticas, juntamente a um horário que permitisse boa alimentação (COELHO, 2009; CAVALIERE, 2009; MAURÍCIO, 2014).

Coelho (2009) afirma que a educação integral também engloba o tempo ampliado/integral na escola, pois ela deve ser constituída de formação e informação e de atividades para a construção da cidadania responsável e participativa. A autora também defende uma educação que mescle as atividades educativas, e não as fragmente, assim como programas implantados no país fazem.

Paro et al (1988) já chamavam a atenção para o fato de que existe um mínimo do acervo cultural, científico, tecnológico, produzido historicamente, a que o ser humano, para viver o seu tempo, precisa ter acesso, em nossa sociedade, independentemente da classe social a que pertença. A escola constitui um espaço sociocultural aonde o aluno vai experimentando uma vivência coletiva e formando uma concepção de mundo, de sociedade e de homem. Porém, o autor defende que a as propostas de extensão diária da escolaridade devem dar prioridade à universalização da escola, em termos de acesso, permanência e efetiva apropriação de parte significativa do saber sistematizado para as amplas camadas de trabalhadores, já que este vem sendo negado à grande parte da população.

Por isso, há também uma enorme importância no tipo de utilização pedagógica das horas adicionais nas quais as crianças permanecem na escola. Entendendo-se essa ampliação do tempo como o período em que as crianças e adolescentes ficam sob responsabilidade da escola, dentro ou fora de suas dependências (CAVALIERE, 2009). Dessa forma, a escola com o tempo ampliado pode ter suas capacidades fortificadas como provedora de socialização e disseminadora cultural. Para isso, é preciso que a ampliação da permanência dos alunos na escola tenha um projeto que além de ser compatível com o processo educativo local esteja articulado com os processos sociais. Para Cavaliere (2009), a ampliação do tempo de escola tem se caracterizado no Brasil sob duas vertentes. Sem apresentar esses modelos como já cristalizados ou de forma antagônica, e sim provocando uma reflexão, a autora traz que nesse momento em que se investem recursos públicos em ambas as direções,

nomearemos um modelo como escola de tempo integral e o outro como aluno em tempo integral. No primeiro, a ênfase estaria no fortalecimento da unidade escolar, com mudanças em seu interior pela atribuição de novas tarefas, mais equipamentos e profissionais com formação diversificada, pretendendo propiciar a alunos e professores uma vivência institucional de 
outra ordem. No segundo, a ênfase estaria na oferta de atividades diversificadas aos alunos no turno alternativo ao da escola, fruto da articulação com instituições multissetoriais, utilizando espaços e agentes que não os da própria escola, pretendendo propiciar experiências múltiplas e não padronizadas (CAVALIERE, 2009, p. 53, grifos nossos).

Por fim, mas sem esgotar a temática, já discutida intensamente desde os anos 80, e que ainda se mantém atual, Paro et al. (1988, p. 17) alegam que "os projetos de escola pública de tempo integral parecem constituir, no momento presente, tentativas de sanar deficiências profundas em duas áreas específicas de políticas sociais - a da educação e a da promoção social".

Uma política pública que teve por objetivo induzir a implantação da política de educação em tempo integral pelos estados e municípios foi o Programa Mais Educação (PME). Existem diversos programas nos níveis municipais e estaduais que desenvolvem o projeto de tempo integral nas escolas, os quais possuem experiências muito diferentes entre si. Em âmbito nacional, o Programa Mais Educação, criado em 2007, pela Portaria Interministerial n. 17/2007, com o intuito de formar em tempo integral os alunos da rede pública de ensino básico, parecia ir na segunda perspectiva apresentada por Cavaliere (2009) do "aluno em tempo integral".

Neste sentido, ampliar o tempo dos discentes sob responsabilidade da escola é fundamental na busca por equidade e maior qualidade na educação brasileira. Mas é preciso ir além quando tratamos de jornada escolar ampliada. É importante considerar que a educação em tempo integral deve propiciar múltiplas oportunidades de aprendizagem por meio do acesso à cultura, arte, esporte, ciência e tecnologia, por meio do acesso a atividades planejadas com intenção pedagógica e articuladas com o projeto político pedagógico da escola, e assim proporcionar ao estudante uma educação integral (SOUSA; ESPIRITO SANTO; BERNADO, 2015).

\section{Procedimentos metodológicos da investigação}

A pesquisa realizada foi de cunho misto, pois trabalhamos com as duas abordagens: a quantitativa e a qualitativa. Para Creswell (2007), o desenvolvimento da investigação mista se dá com o objetivo de reunir dados quantitativos e qualitativos em um único estudo de forma complementar. Com isso, a análise de dados exige procedimentos mais explícitos. O autor relaciona que, para se elaborar uma pesquisa, utilizando-se de abordagem mista, temos que seguir alguns componentes de procedimentos de métodos mistos: natureza da pesquisa 
(informar em uma proposta, uma definição e descrição da técnica); tipos de estratégias (utilização de critérios para escolher uma estratégia); implementação da coleta de dados quantitativos e qualitativos em fases; prioridade à técnica quantitativa ou à qualitativa; integração dos dois tipos de dados, estratégias alternativas e modelos de gráfico; procedimentos de coleta de dados e análise de dados e procedimentos de validação.

O delineamento de pesquisa proposto envolveu, assim, a colaboração entre metodologias quantitativas e qualitativas de pesquisa. À luz da literatura sobre o tema a ser investigado, bem como outras dimensões que a literatura reporta de forma recorrente como sendo capazes de fazer diferença na promoção da eficácia e equidade escolar.

Os sujeitos dessa investigação foram os gestores (diretores, diretores adjuntos, coordenadores pedagógicos e professores comunitários/Coordenadores do PME) das seis escolas investigadas na Grande Tijuca. O critério de escolha das escolas foi o seguinte: a partir das bases do INEP, entre os anos de 2005 e 2013, desenhamos três grupos distintos: escolas que apresentaram melhores desempenhos; escolas que apresentaram piores desempenhos; e, escolas que apresentaram as diferenças mais marcantes de desempenho entre os anos 2011 e 2013 na Região da Grande Tijuca, localizada no município do Rio de Janeiro.

Para o recorte deste artigo, optamos por apresentar parte dos resultados qualitativos por meio das entrevistas realizadas nas escolas investigadas.

\section{Alguns achados da pesquisa: as percepções dos gestores escolares sobre os desafios enfrentados no "chão da escola"}

Os diretores das seis escolas, quando interrogados sobre os desafios e avanços em suas gestões em relação ao Programa Mais Educação, trouxeram mais desafios do que avanços, que vão desde a questão da infraestrutura e da premiação via política de responsabilização até questões relacionadas à formação continuada dos professores e à dificuldade da relação/interação com os docentes mais antigos nas escolas.

É os avanços, eu acredito, acho que a gente conseguiu um espaço para o Mais Educação. Um espaço definitivo para o Mais Educação [...] É. Um dos desafios quando eu entrei para direção, era assim, existe essa questão do IDEB que isso me incomoda muito, essas provas, essas avaliações externas. E que ainda tinha a questão do $14^{\circ}$ salário, que era todo mundo de olho no $14^{\circ}$ salário.

(Diretor, Escola 1, 2015)

Podemos observar que a política de responsabilização (accountability), em geral e no caso do município do Rio de Janeiro, é realizada por incentivos salariais ao final do ano 
(BROOKE, 2006; 2008). Brooke (2008, p. 105) traz que "não há exemplos de programas que usam outras formas de incentivo, tais como recursos adicionais ou vantagens de carreira para membros da equipe escolar". Nesta perspectiva, Franco e Menezes Filho (2012) chamam atenção para o fato da necessidade de termos indicadores educacionais confiáveis de desempenho para as políticas de responsabilização, principalmente quando se trata de premiação, punição ou auxílio para aqueles que podem atingir ou não o desempenho esperado, como mencionado na fala do diretor da Escola 1, com o recebimento ou não do $14^{\circ}$. salário.

Em outro momento da entrevista, quando perguntamos sobre os desafios e avanços da escola, um grande desafio apontado foi o IDEB e um incômodo foi em relação à política de responsabilização que ocasiona no recebimento ou não de uma bonificação/premiação com o $14^{\circ}$ salário, conforme podemos notar no trecho abaixo:

É! Um dos desafios quando eu entrei para direção, era assim, existe essa questão do IDEB que isso me incomoda muito, essas provas, essas avaliações externas. E que ainda tinha a questão do $14^{\circ}$ salário, que era todo mundo de olho no $14^{\circ}$ salário. Isso me incomodou muito, sempre me incomodou muito essa questão do $14^{o}$ salário, e a diretora anterior ela sempre colocou uma questão, quando estava incomodando ela assim... essa questão do "I" [conceito Insuficiente], muito "I". Então, é aluno insuficiente, então a direção era chamada para explicar o porquê de tanto "I", e ai também não ganhava a bonificação, então baixou-se um decreto, não sei se foi só nessa escola ou em outras escolas do Rio, de $10 \%$ só de I. [...] Quando eu entrei para direção eu falei: "Olha, não estou preocupado com $14^{\circ}$ salário, eu quero resultado real da escola". (Diretor, Escola 1, 2015)

A discussão dos problemas e desafios educacionais brasileiros tem sido marcada, nas últimas décadas, pela divulgação dos resultados de avaliações externas e de indicadores educacionais produzidos por avaliações em larga escala dos sistemas de ensino, como por exemplo: SAEB, Prova Brasil, ENEM, ANA, ENADE, entre outras avaliações. Estas avaliações, frequentemente, trazem resultados insatisfatórios que acabam gerando polêmicas em diversos espaços, principalmente nas escolas e, sobretudo, na mídia, acerca das políticas públicas e gestão educacionais. Essa situação pode assumir contornos diferentes quando compreendemos como a avaliação padronizada e em larga escala se inseriu historicamente na gestão da educação no Brasil numa perspectiva diagnóstica.

Bom, um desafio aqui é físico. A parte física. É uma escola tombada [...] um deles é a infraestrutura o outro é a falta de pessoal. Eu não tenho agente educador, não tenho secretário escolar, então isso é muito difícil. Então, eu faço tudo ao mesmo tempo. (Diretor, Escola 4, 2015) 
No que diz respeito especificamente à organização de turmas, estudos (SLAVIN, 1996; DUPRIEZ; DRAELANTS, 2004; GONZÁLEZ, 2002; AGUERRE, 2004; CRAHAY, 2004; 2007) sobre eficácia escolar têm demonstrado a influência da turma e do trabalho docente em sala de aula sobre o desempenho dos alunos. Esses estudos vêm permitindo revelar práticas de composição de turmas e dimensões da atuação pedagógica dos professores relevantes para a compreensão da variação dos resultados obtidos pelos alunos não só de uma mesma turma, mas também entre as turmas de uma mesma escola (BERNADO, 2008; 2016).

O diretor da Escola 4 traz a questão da infraestrutura como um dos grandes desafios da escola. Mas também destaca a ausência de pessoal de apoio na secretaria, inclusive tendo que cobrir faltas e licenças de docentes. Cabe esclarecer que a coordenadora pedagógica desta escola trabalha em horário parcial como professora e no outro horário parcial como coordenadora na mesma escola. Já a diretora adjunta trabalha em horário parcial como professora em outra escola e em horário parcial como adjunta na escola investigada. Durante todo o trabalho de campo ficou nítido o acúmulo de funções do diretor da Escola 4 com vários funcionários adaptados (desviados de suas funções originais) e professores ausentes por conta de licença médica.

A título de conclusão desta seção, podemos perceber pelas falas dos gestores escolares que muitos desafios estavam postos no processo de implementação do PME. Nas unidades escolares do campo de pesquisa foram realizados contatos com situações que fugiam às prerrogativas legais estabelecidas pelo programa. Com relação a este aspecto, chama a atenção a limitada participação dos pais na gestão do programa nas escolas, a influência que a carência de infraestrutura adequada fazia na escolha das oficinas do Mais Educação, bem como o acúmulo de programas e projetos desenvolvidos simultaneamente pelas escolas, o que tornava o PME apenas mais um programa dentre os demais executados pelas unidades escolares.

\section{Considerações finais}

Em consonância com dinâmicas desenhadas no cenário internacional, pesquisadores brasileiros intensificaram a busca pelos fatores que determinam escolas de qualidade e que influenciam positivamente o ensino e o desempenho discente. Franco e Bonamino (2005) indicam que, no Brasil e em outros países da América Latina, ao contrário dos países desenvolvidos, a infraestrutura física da escola e os recursos escolares aparecem como fatores 
fundamentais para o desempenho escolar dos alunos, mesmo quando os resultados são controlados pelo nível socioeconômico dos estudantes. Outros autores (LÜCK, 2000, 2009; BOTLER; MARQUES, 2009) defendem que a gestão é o fator predominante para a melhoria da qualidade da educação. Essa visão se baseia no princípio de que o gestor comprometido com visão da totalidade da escola em seus aspectos administrativos e pedagógicos terá maiores condições de buscar estratégias que visem à melhoria da educação (SILVA, BERNADO, 2012).

Outro fator frequentemente associado à melhoria da qualidade educacional versa sobre a ampliação do tempo de escola (CAVALIERE, 2007). Em geral, este se refere ao tempo diário de permanência dos alunos na escola. De acordo com a autora, mesmo diante da ausência de consensos estabelecidos entre os pesquisadores que apontem uma associação causal direta entre a maior duração do tempo escolar e o aumento do rendimento dos alunos.

Em teoria, as concepções de educação integral e de educação em tempo integral demonstram-se afinadas; sabemos, também, que ambos os seus desenvolvimentos pressupõem uma outra escola. Um novo modelo que se distingue do tradicional, baseado numa suposta igualdade entre os indivíduos e na valorização não somente da educação formal. O Programa Mais Educação refletia bem tais características e, na busca pela identificação dos fatores que impactam a qualidade das escolas, acrescenta a sua aposta à ampliação do tempo e dos espaços escolares, neste caso, a educação integral e a educação em tempo em tempo integral. Na condição de um programa indutor, o Mais Educação agregava a perspectiva de que os territórios que conformam as cidades podem e devem constituir-se em espaços educativos, ampliando, consequentemente, o tempo de escolarização dos alunos.

Diante do exposto, resta refletir se, de fato, iniciativas como a do Programa Mais Educação são capazes de fomentar a melhoria da qualidade educacional. Ou, ao contrário, tais políticas fazem com que as escolas tenham de responder a mais exigências burocráticas que as paralisam diante de uma velha prática que em nada corresponde à ideia de educação integral, entendendo que a mera ampliação do tempo de escola não garante o alcance de sua qualidade.

Neste sentido, ampliar o tempo dos discentes sob responsabilidade da escola em busca por maior equidade e qualidade na educação é ir além do que está posto. Quando tratamos da ampliação da jornada escolar, é importante considerar que essa educação deve propiciar múltiplas oportunidades de aprendizagem articuladas com o projeto político-pedagógico da escola e, assim, proporcionar ao estudante uma educação de fato integral e de qualidade. 
AGRADECIMENTOS: O Projeto de Pesquisa "Escolas Públicas no Estado do Rio de Janeiro e o Programa Mais Educação: uma análise das ações dos gestores escolares em busca de uma educação de qualidade" foi contemplado no Edital FAPERJ n. 25/2014 - Programa "Jovem Cientista do Nosso Estado - 2014" (E-26/201.487/2014).

\section{REFERÊNCIAS}

AGUERRE, T. F. De las "escuelas eficaces" a las reformas de segunda generación. Estudos Sociológicos, V. XXII, n. 2, p. 377-408, 2004.

BARROSO, J. O estudo da autonomia da escola: da autonomia decretada à autonomia construída. BARROSO, J. (Org.). O estudo da escola. Porto: Porto ditora, 1996.

BERNADO, E. da S. Composição social e cognitiva de turmas e desempenho em Leitura e Matemática: como evoluem as desigualdades educacionais? Rio de Janeiro, 2008. 171p. Tese de Doutorado - Departamento de Educação, Pontifícia Universidade Católica do Rio de Janeiro.

BERNADO, E. da S. Formação Docente: que tipo de profissional formar? Boletim Técnico do Senac, Rio de Janeiro, v. 41 n. 3, p. 90-109, set./dez. 2015.

BERNADO, E. da S. Desigualdade educacional: gestão escolar, organização de turmas e desempenho em Leitura e Matemática. Curitiba: Appris/FAPERJ, 173 p, 2016.

BOURDIEU, P.; PASSERON, J.-C. C. A reprodução: elementos para uma teoria do sistema de ensino. 3. ed. Rio de Janeiro: Francisco Alves, 1992.

BOTLER, A. M. H.; MARQUES, L. R. Escola de Gestores: contribuições para a implementação da gestão democrática. ANPAE, 2009.

BRASIL. Constituição da República Federativa do Brasil, de 05 de outubro de 1988.

BRASIL. Portaria Normativa Interministerial n. 17, de 24 de abril de 2007. Institui o Programa Mais Educação que visa fomentar a educação integral de crianças, adolescentes e jovens, por meio do apoio a atividades sócio-educativas no contraturno escolar. Diário Oficial da União, Brasília, DF, 26 abr. 2007.

BRASIL. Decreto n. 7.083, de 27 de janeiro de 2010. Dispõe sobre o Programa Mais Educação. Diário Oficial da União, Brasília, DF, 27 jan. 2010.

BROOKE, N. O futuro das políticas de responsabilização no Brasil. Cadernos de Pesquisa, v. 36, n. 128, p. 377-401, maio/ago. 2006. Disponível em http://www.scielo.br/pdf/cp/v36n128/v36n 128a06.pdf. Acesso em: 01 abr. 2016. 
BROOKE, N. Responsabilização educacional no Brasil. Revista Iberoamericana de Evoluación Educativa, v. 1, p. 93-109, 2008. Disponível em http://www.rinace.net/riee/ numeros/vol1-num1/art7port.pdf. Acesso em: 10 abr. 2016.

CANÁRIO, R. Os estudos sobre a escola: problemas e perspectivas. BARROSO (org.) $\mathbf{O}$ estudo da escola. Porto: Porto Editora, 1996.

CAVALIERE, A. M. V. Tempo de escola e qualidade na educação pública. Educação \& Sociedade, Campinas, v. 28, n. 100 - esp., p. 1015-1035, out. 2007.

CAVALIERE, A. M. V. Escolas em tempo integral versus alunos em tempo integral. Em Aberto. Brasília, v. 22, n. 80, p. 51-63, abr. 2009.

COELHO, L. M. C. da Costa. História(s) da educação integral. Em Aberto. Brasília, v. 22, n. 80, p. 83-96, abr. 2009.

COLEMAN, J. S. et al. Equality of Educational Opportunity. Washington DC: US Government Printing Office, 1966.

CRAHAY, M. Poderá a escola ser justa e eficaz? Da igualdade das oportunidades à igualdade dos conhecimentos. Traduction de L'école peut-elle être juste et efficace? por Vasco Farinha. Lisbonne: Horizontes Pedagógicos, 2004.

CRAHAY, M. Qual pedagogia para os alunos em dificuldade escolar? Cadernos de Pesquisa. v. 37, n. 130, p. 181-208, jan./abr. 2007.

CRESWELL, J. W. Projeto de pesquisa: métodos qualitativo, quantitativo e misto. 2 ed. Porto Alegre: Artmed, 2007.

DUPRIEZ, V.; DRAELANTS, H. Classes homogènes versus classes hétérogènes: les apports de la recherche à l'analyse de la problématique. Cachier de Recherche du GIRSEF. n. 24, p. 1-24, out. 2004.

FRANCO, C.; BONAMINO, A. A pesquisa sobre característica de escolas eficazes no Brasil. Breve revisão dos principais achados e alguns problemas em aberto. Educação on-line. PUCRio. n. 1, p. 1-13, 2005.

FRANCO, A. M. P; MENEZES FILHO, N. Uma análise de rankings de escolas brasileiras com dados do SAEB. Est. Econ. São Paulo, v. 42, n. 2, p. 263-283, abr./jun. 2012. Disponível em: http://www.scielo.br/pdf/ee/v42n2/02.pdf. Acesso em: 10 out. 2016.

GONZÁLEZ, M. T. G. Agrupamiento de alumnos e itinerarios escolares: cuando las aparencias engañan. Educar,29. p. 167-182, 2002.

LÜCK, H. Gestão escolar e formação de gestores. Em Aberto, Brasília, v. 17, n. 72, p. 11-33, fev./jun. 2000.

LÜCK, H. Dimensões da gestão escolar e suas competências. Curitiba: Editora Positivo, 2009. 
MAURÍCIO, L. V. (org.). Tempos e espaços escolares: experiências, políticas e debates no Brasil e no mundo. Rio de Janeiro: Ponteio; FAPERJ, 2014.

MOURA, R. M. A organização escolar: Desigualdades e inovação. s/d. Revista Inovação. Lisboa: Instituto de Inovação Educacional. Disponível em:

http://rmoura.tripod.com/socedu.htm. Acesso em: 10 jan. 2019.

NÓVOA, A. Formação de professores e profissão docente. NÓVOA (org.). Os professores e a sua formação. Lisboa: Publicações Dom Quixote, 1992.

PARO, V. H.; FERRETTI, C. J.; VIANNA, C. P.; SOUZA, D. T. R. de. Escola pública de tempo integral: universalização do ensino e problemas sociais. Cadernos de Pesquisa. São Paulo (65), 1988.

SILVA, F. R., BERNADO, E. S. O ensino municipal de Barra Mansa/RJ (Brasil): em busca de uma escola eficaz. In: Anais [...] III Jornadas nacionales y ii jornadas latinoamericanas de investigadores em formación em educación, Buenos Aires, 2014. Buenos Aires: Instituto de Investigaciones em Ciencias de la Educación da Faculdade de Filosofia e Letras da Universidade de Buenos Aires, 2012, v.1, p. 1-10.

SLAVIN, R. E. Salas de aula eficazes, escolas eficazes: uma base de pesquisa para reforma da Educação na América Latina. PREAL. 1996. Disponível em:

www.cpdoc.fgv.br/projetos/arq/Preal_Doc04.pdf. Acesso em: 10 abr. 2016.

SOUSA, G. J. A.; ESPIRITO SANTO, N. C.; BERNADO, E. S. A. A sexta meta do PNE 2014-2024: um diálogo possível em busca de uma educação integral e(m) tempo integral.

EccoS, São Paulo, n. 37, p. 143-160. maio/ago. 2015.

\section{Como referenciar este artigo}

BERNADO, E. da S. Educação em tempo integral: alguns desafios para a gestão escolar. Revista Ibero-Americana de Estudos em Educação, Araraquara, v. 15, n. 1, p. 79-94, jan./mar. 2020. e-ISSN: 1982-5587. DOI: https://doi.org/10.21723/riaee.v15i1.12116

Submetido em: 26/01/2019

Revisões requeridas: 26/03/2019

Aprovado em: 20/07/2019

Publicado em: 02/01/2020 